\title{
Occupational Burnout and Severe Injuries: An Eight-year Prospective Cohort Study among Finnish Forest Industry Workers
}

\author{
Kirsi Ahola $^{1}$, Simo Salminen ${ }^{1}$, Salla Toppinen-Tanner ${ }^{1}$, Aki Koskinen ${ }^{2}$ and \\ Ari VÄÄNÄNEN ${ }^{1}$
}

${ }^{1}$ Development of Work and Work Organizations, Finnish Institute of Occupational Health, Finland and ${ }^{2}$ Creating Solutions, Finnish Institute of Occupational Health, Finland

\begin{abstract}
Occupational Burnout and Severe Injuries: An Eight-year Prospective Cohort Study among Finnish Forest Industry Workers : Kirsi AHOLA, et al. Development of Work and Work Organizations, Finnish Institute of Occupational Health, FinlandObjectives: Burnout is a psychological consequence of prolonged work stress. Studies have shown that it is related to physical and mental disorders. The safety outcomes of burnout have been studied to a lesser extent and only in the work context. This study explored the effect of burnout on future severe injuries regardless of their context. Methods: A total of 10,062 forest industry employees (77\% men, 63\% manual workers) without previous injuries participated in 1996 or 2000 in the "Still Working" study examining the work-related antecedents of health and mortality. Burnout was assessed using the Maslach Burnout Inventory-General Survey. Injuries leading to death or hospitalization were regarded as severe. We extracted such injuries from independent national registers. The relationship between burnout and new injuries was analyzed using Cox proportional regression. The analyses were adjusted for age, sex, marital status, and occupational status. Results: There were 788 new injuries over eight years. Injuries were more common among male and manual workers. After adjustments, each one-unit increase in the burnout score was related to a $9 \%$ increase in the risk of injury (95\% confidence interval: 1.02-1.17). Experiencing symptoms at least monthly
\end{abstract}

Received Jan 29, 2013; Accepted Jul 16, 2013

Published online in J-STAGE Oct 26, 2013

Correspondence to: K. Ahola, Finnish Institute of Occupational Health, Topeliuksenkatu 41 a A, FI-00250 Helsinki, Finland (email: kirsi.ahola@ttl.fi)

Type of contribution: KA planned the design with AV, SS, and ST-T; $A V$ and ST-T gathered the data; $A K$ performed the analysis; KA wrote the first draft of the manuscript; and all authors participated in the editing of the final version of the manuscript. was related to a 1.18-fold adjusted injury risk $(95 \% \mathrm{Cl}$ : 1.02-1.36). Of the subscales of burnout, exhaustion and cynicism but not lack of professional efficacy predicted injuries after adjustments. Conclusions: In addition to mental and physical disorders, burnout predicts severe injuries. Developing work conditions and optimizing workload may enhance safety and decrease health expenses related to all injuries.

(J Occup Health 2013; 55: 450-457)

Key words: Accidents, Burnout, Health, Injuries, Safety

Occupational burnout develops from the interplay between individual and environmental factors at work $^{1)}$. In its general form, counteracted in all kinds of work, burnout is manifested as exhaustion, cynicism, and diminished professional efficacy ${ }^{2}$. The prevalence of burnout symptoms has been around $28-52 \%$ in Finnish working populations ${ }^{3,4}$.

The risk of burnout is elevated when a discrepancy prevails between job demands and job resources ${ }^{5)}$. Longitudinal studies have found that high quantitative and qualitative workloads, role conflict and ambiguity, low predictability, experienced unfairness, and lack of participation and social support are environmental risk factors for burnout ${ }^{1,6,7)}$. Individual factors interact with environmental factors, resulting in either the acceleration of or buffering against the development of burnout ${ }^{1)}$. For instance, research has shown that employees with a low sense of coherence, high neuroticism, low extraversion, low agreeableness, and low conscientiousness are more prone to burnout than others $^{8-10)}$.

Burnout can have adverse consequences regarding health and work ability. In prospective designs, burnout has predicted coronary heart disease ${ }^{11)}$, type 2 diabetes ${ }^{12)}$, common infections ${ }^{13)}$, musculoskeletal 
pain $^{14)}$ and depressive symptoms ${ }^{15)}$. In addition, burnout has predicted sickness absences ${ }^{16)}$ and disability pensions ${ }^{17)}$. However, there are fewer studies investigating burnout and safety outcomes, and they examined injuries that occurred in the work place ${ }^{18)}$.

Burnout is a chronic condition that typically prevails and remains stable over time ${ }^{6,15}$. It has been shown that burnt-out individuals suffer from severe fatigue throughout the day ${ }^{19)}$ and that burnout easily spills over to other life domains ${ }^{20)}$. Therefore, it is possible that burnout will increase the risk of all kinds of injuries, not just the ones occurring at work. This is worth studying, as injuries are common among working populations but less than one-third of injuries occur at work ${ }^{21)}$.

There are many possible mechanisms that may link burnout to all-cause injuries ${ }^{18)}$. To behave safely and reasonably, people must be capable of utilizing their full mental capacity. In order to avoid injuries, people must also be motivated to extend effort and perform actions safely. However, when burnt out, a person's energy may be insufficient for behaving thoughtfully and remembering to follow instructions. They may not have enough capacity left to master the best ways to do things ${ }^{22}$. It has been shown by previous research that burnout may compromise cognitive functioning and prevent individuals from responding appropriately to novel, changing, or complicated tasks or situations ${ }^{23,24)}$. On the other hand, burnt-out people may be cynical and skip phases or procedures in their actions because they do not find it worthwhile to invest time and energy into them. These two possible explanations, that is, a low level of energy and a cynical attitude, suggest that especially the exhaustion and cynicism subscales of burnout may predict future injuries.

Because burnout is likely to influence health and safety outcomes in various ways, it probably has an impact on several types of injuries. Thus, in the same way that burnout has been shown to relate to both physical $^{11-14)}$ and mental illnesses ${ }^{4,25)}$, it is probable that burnout will predispose employees to all kinds of injuries, i.e., make people generally prone to injuries in all spheres of life.

It is possible that some injuries could be prevented by increasing the understanding and prevention of the circumstances associated with injuries ${ }^{26)}$. However, injuries cannot be prevented by focusing only on environmental factors, since there are always human factors involved in the process. Earlier research has shown that stress and fatigue are possible risk factors for injuries ${ }^{27-31)}$. Therefore, studying the relationship between burnout and all-cause injuries might contribute to more thorough preventive strategies regarding injuries.
In the present study, we aimed to investigate whether occupational burnout, assessed with the general version of the Maslach Burnout Inventory ${ }^{2}$, is related to an increased risk of severe injuries. We extracted all injuries, regardless of their context, that led to the hospitalization or death of a worker from independent national registers in an eight-year prospective design. We expected burnout, especially its exhaustion and cynicism subscales, to be related to all major types of all-cause injuries.

\section{Materials and Methods}

\section{Procedure}

This study is a part of the ongoing "Still Working" cohort study that is examining work-related antecedents of health, morbidity, and mortality in a multinational private sector forest industry corporation ${ }^{32)}$. In spring 1996 and autumn 2000, questionnaires on psychosocial factors and well-being were sent to the participating work units, distributed to employees by their supervisors and once completed, mailed directly to the Finnish Institute of Occupational Health. Participation was voluntary, and confidentiality was assured to all employees. We obtained the approval of the Ethics Committee of the Finnish Institute of Occupational Health for the study.

The data from registers were linked to the survey responses of all respondents by each participant's personal identity code, which is given to all Finns at birth and used for all contacts with health-care. The researchers gave each employee in the corporation an identification code, which was marked in the questionnaire. The link between the code and the personal identification number was known only to the researchers.

\section{Participants}

In the spring of 1996 , the questionnaire was sent to 15,466 Finnish employees of the large multinational forest industry corporation, and in the autumn of 2000 , it was sent similarly to 12,940 Finnish employees. Participation in the study was voluntary. A total of 9,705 employees chose to respond to the questionnaire in 1996 (response rate 63\%), and 7,850 employees chose to respond in $2000(61 \%)$. We excluded those who had already responded in 1996 from the 2000 cohort; thus, the final cohort consisted of 10,983 employees.

Of this base population, the 249 people (189 in 1996, 60 in 2000) who, according to the Finnish Hospital Discharge Register, had already been treated as in-patients for injuries during the two years preceding baseline, were excluded. Furthermore, 672 people were excluded due to missing values in the relevant questionnaire items, leaving 10,062 employees in 
the final study population. Men (53\% versus $45 \%$, $p<0.001)$, non-manual workers $(37 \%$ versus $25 \%$, $p<0.001)$, and younger (under 45$)$ workers $(77 \%$ versus $68 \%, p<0.001)$ were overrepresented in the study sample compared with those excluded, whereas no difference emerged regarding marital status $(p=0.51)$.

\section{Ascertaining severe injuries}

Severe injuries were defined as injuries leading to death or hospitalization due to an external cause on the basis of the International Statistical Classification of Diseases and Related Health Problems (ICD-10) ${ }^{33)}$. The ICD-10 diagnosis codes used were V01-V99 (transport accidents), W00-W19 (falls), W20-W99 (other external causes of accidental injury), X00-X57 (exposure to the forces of nature) and X58-X59 (accidental exposure to unspecified factors).

First, the dates and causes of death on the death certificates were extracted from the National Mortality Register maintained by Statistics Finland from 1 March 1996 to 31 December 2008. Next, information on hospital admissions was derived from the National Hospital Discharge Register maintained by the National Institute for Health and Welfare from 1 March 1994 to 31 December 2008. Information on admission and discharge as well as on the diagnosis of each patient is included in this database. Data on hospital admissions during the two years before baseline (1 March 1994 to 28 February 1996 or 1 October 1998 to 30 September 2000) were used to exclude those with injuries already. Severe injuries were extracted for approximately eight years after baseline, i.e., either from 1 March 1996 to 31 May 2004 or from 1 October 2000 to 31 December 2008.

\section{Assessment of burnout}

Burnout was measured using the Maslach Burnout Inventory-General Survey (MBI-GS $)^{2,34)}$. This survey consists of three subscales. Exhaustion (five items, Cronbach's alpha=0.87) refers to feelings of overstrain, tiredness and fatigue. Cynicism (five items, $\alpha=0.76$ ) reflects an indifferent and distant attitude toward work. Professional efficacy (six items, $\alpha=0.83$ ) consists of feelings of competence and accomplishment in one's work. Satisfactory reliability and validity of the MBI-GS have been confirmed ${ }^{35,36)}$. In the present study, one of the cynicism items was left out due to its low correlation with the other cynicism items ( $\alpha=0.83$ afterwards). The items were scored on a seven-point frequency rating scale ranging from 0 (never) to six (daily). One missing value per subscale was allowed. High exhaustion and cynicism scores and low professional efficacy scores indicate burnout. Therefore, the items of professional efficacy were reversed. A summary score, in which exhaus- tion, cynicism, and diminished professional efficacy had different weights $(0.4 \times$ exhaustion $+0.3 \times$ cynicism $+0.3 \times$ diminished professional efficacy), was calculated $^{8)}$. We also categorized the burnout and subscale scores according to the approximate frequency of symptoms as follows: no burnout (sum score 0 to 1.49) and burnout (sum score 1.50 to 6 ). According to this categorization, a person was coded as a case when he or she experienced symptoms approximately monthly or more often ${ }^{8,34)}$.

\section{Assessment of sociodemographic factors}

Sociodemographic factors, i.e., age, sex, marital status, and occupational status, were used as covariates in the analyses because they have been shown to relate to the level of burnout or injuries ${ }^{25,26)}$. We obtained data on age, sex, and marital status from the National Population Register Centre. Marital status was dichotomized as married versus unmarried. Occupational status was elicited from employer's records and dichotomized as manual (i.e., production and maintenance) or non-manual (i.e., supervision, research, development and office work).

\section{Statistical analysis}

We analyzed the associations between burnout and injuries using Cox proportional hazard regression. For each participant, person-days of follow-up were calculated either from 1 March 1996 to death, severe injury or 31 May 2004, whichever came first, or from 31 October 2000 to death, severe injury or 30 September 2008. The mean length of the follow-up was 7 years 11 months (range from 0 years to 8 years 3 months). Hazard ratios (HRs) and their 95\% confidence intervals (CIs) provided risk estimates associated with burnout. Burnout was first used as a standardized continuous variable and then as a dichotomized variable of no burnout versus mild or severe burnout. We examined the time-dependent interaction terms between burnout and the subscales and the logarithm of the follow-up period to confirm that the proportional hazard assumptions were justified. The significance of the interaction effects on injuries between burnout scales, and sex and age group (below or over 45 years) of the respondents was tested by including the interaction terms in the models. The analyses were first adjusted for personal factors (age, sex and marital status) and then additionally for work-related factors (occupational status) at baseline. Two-tailed p-values below 0.05 were considered to indicate statistical significance. We performed the analyses using the SAS statistical analysis software, version 9.1.

\section{Results}

The majority of the study participants were male 
Table 1. Baseline characteristics of the study population by burnout

\begin{tabular}{|c|c|c|c|c|}
\hline \multirow{2}{*}{ Characteristic } & All & No burnout & Burnout & Statistics \\
\hline & $\mathrm{n}(\%)$ & $\mathrm{n}(\%)$ & $\mathrm{n}(\%)$ & $p$-value \\
\hline Sex & & & & $<0.001$ \\
\hline Men & 7,747 (77) & 4,769 (79) & $2,978(74)$ & \\
\hline Women & $2,315(23)$ & $1,258(21)$ & $1,057(26)$ & \\
\hline Marital status & & & & 0.110 \\
\hline Unmarried & $3,605(36)$ & $2,065(34)$ & $1,540(38)$ & \\
\hline Married & $6,457(64)$ & $3,962(66)$ & $2,495(62)$ & \\
\hline Occupational status & & & & $<0.001$ \\
\hline Manual & $6,302(63)$ & $3,610(60)$ & $2,692(67)$ & \\
\hline Non-manual & $3,780(37)$ & $2,417(40)$ & $1,343(33)$ & \\
\hline
\end{tabular}

(77\%), married (64\%), and manual workers $(63 \%)$. The mean age of the participants was 43 (standard deviation 9, range from 16 to 65 ) at the beginning of the study. The characteristics of the study population are presented in Table 1. There was no statistically significant age difference between those with and those without burnout $(p=0.11)$.

Altogether, $40 \%$ of the participants experienced symptoms of burnout. Those with symptoms of burnout were more often female and manual workers (Table 1).

The time-dependent interaction terms between burnout scales and the logarithm of the follow-up period were all nonsignificant $(p>0.19)$, indicating that the association between burnout and injuries was not moderated by the time elapsed between the survey and injury, therefore justifying the use of proportional hazard models. The interaction effects between burnout and sex or age group on injuries were not statistically significant $(p>0.32)$.

During the approximately eight-year follow-up, a total of 788 injuries occurred (8\%). Most of them led to hospitalization $(\mathrm{n}=773)$, and 15 led to death. The most common types of injuries were falls (59\%). Injuries were related to sex and occupational status, and were more common among men and manual workers (Table 2).

Burnout was related to the risk of injury. Each one-unit increase in the standardized burnout summary score was related to a $10 \%$ increase in the risk for severe injuries (95\% CI: 1.03-1.17). The association remained significant after adjustments $(H R=1.09$, 95\% CI: 1.02-1.17). Of the dimensions of burnout, exhaustion was related to a $9 \%$ (95\% CI: 1.02-1.17) increase in the risk for severe injuries, and cynicism was related to a $10 \%$ (95\% CI: 1.03-1.18) increase in the risk for severe injuries. These associations remained significant after adjustments $(\mathrm{HR}=1.12,95 \%$ CI: $1.05-1.20$, and $\mathrm{HR}=1.09$, 95\% CI: $1.02-1.16$, respectively). Lack of professional efficacy was not related to subsequent injuries $(\mathrm{HR}=1.02,95 \% \mathrm{CI}$ : 0.95-1.09).

When dichotomized as at least monthly or less frequent symptoms, burnout was related to a $19 \%$ increase in the risk of injury. The association remained significant $(\mathrm{HR}=1.18,95 \% \mathrm{CI}$ : 1.02-1.36) after adjustment for age, sex, marital status, and occupational status (Table 3). When dichotomized, exhaustion was also related to a $19 \%$ increase in the risk of injury. After adjustments, the hazard ratio of exhaustion contributing to injuries was 1.24 (95\% CI: 1.08-1.43). Dichotomized cynicism was related to a $20 \%$ increase in the risk of injury, and the association remained significant after adjustments $(\mathrm{HR}=1.17,95 \%$ CI: 1.01-1.34). Dichotomized lack of personal efficacy was not related to the risk of injury (Tables 2 and 3). There was no statistically significant difference in the type of injury between the employees with burnout and those without burnout $(p<0.42$; Table 4$)$.

\section{Discussion}

In this prospective cohort study linking survey data to independent national registers, burnout and its exhaustion and cynicism subscales were related to severe register-based injuries during an eightyear follow-up among forest industry workers, after sex, age, marital status, and occupational status of the participants at baseline were taken into account. There was no association between the third subscale of burnout, diminished professional efficacy and severe injuries. Type of injury was not related to burnout.

The obtained results regarding the association between burnout and register-based subsequent severe injuries are in line with previous results concerning burnout and occupational injuries. A recent metaanalysis that found nine studies on burnout and safety outcomes at work concluded that a low but signifi- 
Table 2. Unadjusted hazard ratios (HRs) and their 95\% confidence intervals (CIs) for severe injuries during 8 years of follow-up in relation to characteristics of the study population $(n=10,062)$

\begin{tabular}{|c|c|c|}
\hline \multirow{2}{*}{ Characteristic } & \multicolumn{2}{|c|}{ Severe injury } \\
\hline & $\mathrm{n}$ (cases) & HR $(95 \%$ CI $)$ \\
\hline \multicolumn{3}{|l|}{ Sex } \\
\hline Women & $2,315(121)$ & 1.00 (ref.) \\
\hline Men & $7,747(667)$ & $1.69(1.39-2.05)$ \\
\hline \multicolumn{3}{|l|}{ Marital status } \\
\hline Married & $6,457(485)$ & 1.00 (ref.) \\
\hline Unmarried & $3,605(303)$ & $1.13(0.98-1.30)$ \\
\hline \multicolumn{3}{|c|}{ Occupational status } \\
\hline Non-manual & $3,760(208)$ & 1. 00 (ref.) \\
\hline Manual & $6,302(580)$ & $1.70(1.45-2.00)$ \\
\hline \multicolumn{3}{|l|}{ Burnout } \\
\hline No & $6,027(440)$ & 1.00 (ref.) \\
\hline Yes & $4,035(348)$ & $1.19(1.04-1.37)$ \\
\hline \multicolumn{3}{|l|}{ Exhaustion } \\
\hline No & $6,451(462)$ & 1.00 (ref.) \\
\hline Yes & $3,611(312)$ & $1.19(1.03-1.37)$ \\
\hline \multicolumn{3}{|l|}{ Cynicism } \\
\hline No & $6,312(462)$ & 1.00 (ref.) \\
\hline Yes & $3,750(326)$ & $1.20(1.04-1.38)$ \\
\hline \multicolumn{3}{|l|}{ Lack of PE } \\
\hline No & $5,855(453)$ & 1.00 (ref.) \\
\hline Yes & $4,207(338)$ & $1.03(0.90-1.19)$ \\
\hline
\end{tabular}

Table 3. Adjusted hazard ratios (HRs) and their 95\% confidence intervals (CIs) for severe injuries during 8 years of follow-up in relation to burnout and its subdimensions $(n=10,062)$

\begin{tabular}{lll}
\hline \multirow{2}{*}{ Level of symptoms } & \multicolumn{2}{c}{ Severe injury } \\
\cline { 2 - 3 } & \multicolumn{1}{c}{ Model 1} & \multicolumn{1}{c}{ Model 2} \\
\cline { 2 - 3 } & \multicolumn{1}{c}{ HR $(95 \%$ CI) } & \multicolumn{1}{c}{ HR $(95 \%$ CI) } \\
\hline Burnout & 1.00 (ref.) & 1.00 (ref.) \\
$\quad$ No & $1.21(1.05-1.40)$ & $1.18(1.02-1.36)$ \\
Yes & & \\
Exhaustion & 1.00 (ref.) & 1.00 (ref.) \\
No & $1.23(1.06-1.42)$ & $1.24(1.08-1.43)$ \\
Yes & & \\
Cynicism & 1.00 (ref.) & 1.00 (ref.) \\
No & $1.21(1.05-1.39)$ & $1.17(1.01-1.34)$ \\
Yes & & \\
Lack of PE & 1.00 (ref.) & 1.00 (ref.) \\
No & $1.04(0.90-1.20)$ & $0.99(0.86-1.15)$ \\
$\quad$ Yes &
\end{tabular}

PE, professional efficacy. Model 1 is adjusted for sex, age, and marital status at baseline. Model 2 is adjusted for sex, age, marital status, and occupational status at baseline.

PE, professional efficacy.

Table 4. Types of injury according to burnout

\begin{tabular}{|c|c|c|c|c|}
\hline \multirow{2}{*}{ Type of injury } & \multirow{2}{*}{ ICD-10 code } & All & Burnout & No burnout \\
\hline & & $\mathrm{n}(\%)$ & $\mathrm{n}(\%)$ & $\mathrm{n}(\%)$ \\
\hline Falls & W00-W19 & $463(58.8)$ & $199(57.2)$ & $264(60.0)$ \\
\hline Other external cause of accidental injury & W20-W99 & 99 (12.6) & $50(14.4)$ & $49(11.1)$ \\
\hline Accidental exposure to unspecified factors & X58-X59 & $96(12.2)$ & $39(11.2)$ & $57(13.0)$ \\
\hline Transport accidents & V01-V99 & $91(11.5)$ & $39(11.2)$ & $52(11.8)$ \\
\hline Exposure to the forces of nature & X00-X57 & $39(4.9)$ & $21(6.0)$ & $18(4.1)$ \\
\hline All & V01-X59 & $788(100)$ & $348(100)$ & $440(100)$ \\
\hline
\end{tabular}

cant positive correlation existed between burnout and adverse safety outcomes ${ }^{18)}$. In that study, burnout was defined in the protocol as worker anxiety, health, depression and work-related stress, i.e., general psychological distress. In addition, safety outcomes in the workplace included all possible injuries and those that had occurred in people other than workers, for example, patients. Furthermore, the studies reviewed suffered from common method bias because burnout and safety outcomes were self-reported. The present study confirmed that occupational burnout is related to all-cause register-based severe injuries of the employees. It was also shown that burnout may spill over to other life domains ${ }^{20)}$ and that the consequences of burnout may spread from the work context.

The types of injury were quite similar among the employees with burnout and among those with no burnout. This suggests that even though burnout is related to the risk of injury, it is not related to specific types of injury. However, it was not possible 
in the present study to make a distinction between occupational and other injuries. Therefore, our results are preliminary, and more research is needed on the relationship between burnout and especially the type of injury.

In the present study, the exhaustion and cynicism subscales of burnout were related to an increased risk of injury, but diminished professional efficacy was not. Therefore, the importance of having enough energy and motivation to comply was supported and both were supported as possible explanations for the association between burnout and injuries ${ }^{18)}$. In addition, the result showing that only the exhaustion and cynicism subscales of burnout are related to injuries further supports the previous suggestions that exhaustion and cynicism constitute the primary dimensions of burnout syndrome and that the third subscale, lack of professional efficacy, might be a related but a separate entity ${ }^{37}$.

Burnout has been shown to relate to both physical $^{11-13,38)}$ and mental illnesses ${ }^{4,25)}$. Therefore, co-occurring illnesses or their subclinical phases may also decrease the resources of a worker and increase the risk of injury ${ }^{39)}$. According to eleven studies, the relationships between mental ill-health and risk of injury in the workplace are mixed ${ }^{40)}$. Although the majority of studies on depression have observed a significant association between depression and injury, one study did not find any such association, and some studies found that association existed among only men or women. Another study found that the strength of the association between depressive symptoms and risk of injury depended on the persistence of the symptoms ${ }^{41)}$. Therefore, the mechanisms and causal links between burnout, health and injuries need to be further studied.

Some limitations must be taken into consideration in this study. First, we used a nonrandom sample of one occupational branch. Although the target organization employs heterogeneous personnel with jobs ranging from production to managerial work, the majority of the study sample comprised manual workers. Further, we used data on the type of work very crudely, only dividing it based on the levels of whitecollar or blue-collar work. However, it has been shown that burnout can evolve in all types of work and that the process of burning out is similar among blue- and white-collar workers ${ }^{42}$. However, caution is warranted regarding generalization of these results to other, dissimilar populations. These findings need to be replicated and studied in more detail in regard to possible confounding factors in representative samples.

The original response rate was $63 \%$. Although it can be regarded as a satisfactory level in relation to observational studies in general, many workers were lost. Fortunately, the mortality and hospitalization data was $100 \%$ complete and covered all employees, so there was no attrition regarding the outcome due to the degree of burnout.

In the final sample, male, younger and non-manual workers were somewhat overrepresented compared with those excluded. In population samples, younger and non-manual workers tend to suffer from burnout to a lesser degree than others ${ }^{25,43)}$. However, the risk of burnout did not differ between sexes in the Finnish working population ${ }^{25)}$. In addition, there was no significant interaction effect between sex and burnout on injuries in the present study.

We excluded those who at baseline had already been treated for an injury in the last two years. We did not take employees' health status at baseline into account in any other way. Existing illnesses may also affect the risk of injury, or illnesses may have been an unmeasured underlying factor behind both burnout and injuries. More research is needed to clarify the mechanisms between burnout and injuries. In addition, we assessed burnout only once, at baseline. Therefore, we do not know how long-lasting the exposure was. However, based on previous studies, we know that burnout tends to be very stable ${ }^{6,15}$. Finally, we were not able to control for the health-related behavior of the employees because these factors were not covered in this phase of the data collection of the "Still Working" study. Alcohol use or physical activity may also affect risk of injury, but this remains to be analyzed in future studies.

We used the general version of the most widely used burnout instrument ${ }^{2}$. A nationally established procedure was used to form a weighted summary score for the burnout syndrome and to dichotomize $\mathrm{it}^{8,34)}$. In this formula, the weights were chosen on the basis of a discriminant function analysis with several health-related variables used as dependent variables $^{3)}$. We also categorized burnout according to the approximate frequency of the symptoms. We preferred this way, which has revealed a significant relationship with several health-related associates of burnout ${ }^{4,38,44)}$, to the alternative ways of categorizing burnout, for example, on the basis of the relative distribution of burnout symptoms in a population ${ }^{45}$.

We used all injuries as the outcome, not only those that occurred in the work context. Nonfatal injuries are common in working-age adults in the US. About $30 \%$ of them are workrelated ${ }^{21}$. It also has been shown that burnt-out individuals suffer from severe fatigue throughout the day ${ }^{19)}$ and that burnout may spill over to other life domains ${ }^{20)}$. Therefore, if the worker is burned out, he or she may be injured also outside the work domain, for example, during commutation, at home, or in leisure time. We 
extracted severe injuries leading to death or to hospital discharge because in Finland they are nationally registered and a medical diagnosis is always given as the reason for death and hospitalization. In this way, the data on severe injuries were complete, and the use of independent national register data for exclusion, adjustment, and assessment of the outcome helped us to avoid common method bias.

To conclude, the results of this study show that burnout is a risk factor for future severe all-cause injuries. Therefore, enhancing the balance between environmental demands and resources at work might diminish the risk of burnout and improve the possibilities and motivation of people to behave safely and avoid risks in all domains of life. Consequently, the probability of injuries might decrease, which could lead to financial savings.

Acknowledgments: $\mathrm{AK}$ and AV were financially supported by the Academy of Finland (project \#267172). The authors are grateful to all study participants and the Still Working Study group members. We warmly thank Mrs Alice Lehtinen for the linguistic editing of the text.

\section{References}

1) Schaufeli WB, Enzmann D. The burnout companion to study and practice: a critical analysis. London: Taylor \& Francis; 1998.

2) Maslach C, Jackson SE, Leiter MP. Maslach Burnout Inventory Manual. Palo Alto (CA): Consulting Psychologists Press; 1996.

3) Kalimo R, Toppinen S. Burnout among Finnish working population. Helsinki: Työterveyslaitos; 1997 (in Finnish).

4) Ahola K, Honkonen T, Isometsä $E$, et al. The relationship between job-related burnout and depressive disorders-results from the Finnish Health 2000 Study. J Affect Disord 2005; 88: 55-62.

5) Schaufeli WB, Bakker AB. Job demands, job resources, and their relationship with burnout and engagement: a multi-sample study. J Organ Behav 2004; 25: 293-315.

6) Borritz M, Bültmann U, Rugulies R, Christensen KB, Villadsen E, Kristensen T. Psychosocial work characteristics as predictors for burnout: Findings from 3-year follow up of the PUMA study. J Occup Environ Med 2005; 47: 1015-25.

7) Maslach C, Leiter MP. Early predictors of job burnout and engagement. J Appl Psychol 2008; 93: 498-512.

8) Kalimo R, Pahkin K, Mutanen P, Toppinen-Tanner S. Staying well or burning out at work: work characteristics and personal resources as long-term predictors. Work Stress 2003; 17: 109-22.

9) Swider BW, Zimmerman RD. Born to burnout: a meta-analytic path model of personality, job burn- out, and work outcomes. J Vocational Behav 2010; 76: 487-506.

10) Armon G, Shirom A, Melamed S. The big five personality factors as predictors of change across time in burnout and its facets. J Pers 2012; 80: 403-27.

11) Toker S, Melamed S, Berliner S, Zeltser D, Shapira I. Burnout and the risk of coronary heart disease: a prospective study of 8,838 employees. Psychosom Med 2012; 74: 840-7.

12) Melamed S, Shirom A, Toker S, Shapira I. Burnout and risk of type 2 diabetes: a prospective study of apparently healthy employed persons. Psychosom Med 2006; 68: 863-9.

13) Mohren DC, Swaen GM, Kant IJ, van Amelsvoort LG, Borm PJ, Galama JM. Common infections and the role of burnout in a Dutch working population. J Psychosom Res 2003; 55: 201-8.

14) Armon G, Melamed S, Shirom A, Shapira I. Elevated burnout predicts the onset of musculoskeletal pain among apparently healthy employees. J Occup Health Psychol 2010; 15: 399-408.

15) Hakanen JJ, Schaufeli WB. Do burnout and work engagement predict depressive symptoms and life satisfaction? Three-wave seven-year prospective study. J Affect Disord 2012; 141: 415-24.

16) Toppinen-Tanner $S$, Ojajärvi $A$, Väänänen $A$, Kalimo $\mathrm{R}$, Jäppinen P. Burnout as a predictor of medically certified sick-leave absences and their diagnosed causes. Behav Med 2005; 31: 18-27.

17) Ahola K, Gould R, Virtanen M, Honkonen T, Aromaa A, Lönnqvist J. Occupational burnout as a predictor of disability pension: a populationbased cohort study. Occup Environ Med 2009; 66: 284-90.

18) Nahrgang JD, Morgeson FP, Hofmann DA. Safety at work: a meta-analytic investigation of the link between job demands, job resources, burnout, engagament, and safety outcomes. J Appl Psychol 2011; 96: 71-94.

19) Sonnenschein M, Sorbi MJ, van Doornen LJ, Schaufeli WB, Maas CJ. Electronic diary evidence on energy erosion in clinical burnout. J Occup Health Psychol 2007; 12: 402-13.

20) Kinnunen U, Feldt T, Geurts S, Pulkkinen L. Types of work-family interface: well-being correlates of negative and positive spillover between work and family. Scand J Psychol 2006; 47: 149-62.

21) Smith GS, Wellman HM, Sorock GS, et al. Injuries at work in the US adult population: contributions to the total injury burden. Am J Public Health 2005; 95: 1213-9.

22) Halbesleben JRB. The role of exhaustion and workarounds in predicting occupational injuries: a crosslagged panel study of health care personnel. J Occup Health Psychol 2010; 15: 1-16.

23) Sandström A, Rhodin IN, Lundberg M, Olsson $\mathrm{T}$, Nyberg L. Impaired cognitive performance in patients with chronic burnout. Biol Psychol 2005; 69: 271-9. 
24) Oosterholt BG, Van der Linden D, Maes JHR, Verbraak MJPM, Kompier MAJ. Burned out cognition-cognitive functioning of burnout patients before and after a period with psychological treatment. Scand J Work Environ Health 2012; 38: 358-69.

25) Ahola K, Honkonen T, Kivimäki $M$, et al. Contribution of burnout to the association between job strain and depression: the Health 2000 Study. J Occup Environ Med 2006; 48: 1023-30.

26) Wilkins K, McKenzie SG. Work injuries. Health Reports 2007; 18: 1-18.

27) Salminen S, Kivimäki M, Elovainio M, Vahtera J. Stress factors predicting injuries of hospital personnel. Am J Industrial Med 2003; 44: 32-6.

28) Swaen GM, van Amelsvoort LP, Bultmann U, Kant IJ. Psychosocial work characteristics as risk factors for being injured in an occupational accident. $J$ Occup Environ Med 2004; 46: 521-7.

29) Nakata A, Ikeda $T$, Takahashi $M$, et al. Impact of psychosocial job stress on non-fatal occupational injuries in small and medium-sized manufacturing enterprises. Am J Industrial Med 2006; 49: 658-69.

30) Ghosh AK, Bhattacherjee A, Chau N. Relationship of working conditions and individual characteristics to occupational injuries: a case-control study in coal miners. J Occup Health 2004; 46: 470-8.

31) Arlinghaus A, Lombardi DA, Willetts JL, Folkard S, Christiani DC. A structural equation modeling approach to fatigue-related risk factors for occupational injury. Am J Epidemiol 2012; 176: 597-607.

32) Väänänen A, Koskinen A, Joensuu M, et al. Lack of predictability at work and risk of acute myocardial infarction: an 18-year prospective study of industrial employees. Am J Public Health 2008; 98: 2264-71.

33) The ICD-10 Classification of Mental and Behavioural Disorders: Clinical Descriptions and Diagnostic Guidelines. Geneva (Switzerland): World Health Organization; 1992.

34) Kalimo R, Hakanen J, Toppinen-Tanner S. The Finnish version of Maslach's Burnout InventoryGeneral Survey. Helsinki (Finland): Finnish Institute of Occupational Health; 2006 (in Finnish).

35) Taris TW, Schreurs PJG, Schaufeli WB. Construct validity of the Maslach Burnout Inventory-General Survey: two sample examination of its factor struc- ture and correlates. Work Stress 1999; 13: 223-37.

36) Schutte N, Toppinen S, Kalimo R, Schaufeli WB. The factorial validity of the Maslach Burnout Inventory-General Survey (MBI-GS) across occupational groups and nations. J Occup Organ Psychol 2000; 73: 53-66.

37) Lee RT, Ashforth BE. A longitudinal study of burnout among supervisors and managers: comparisons between the Leiter and Maslach (1988) and Golembiewski et al. (1986) models. Organ Behav Hum Dec 1993; 54; 369-98.

38) Honkonen T, Ahola K, Pertovaara M, et al. The association between burnout and physical illness in the general population-results from the Finnish Health 2000 Study. J Psychosom Res 2006; 61: 59-66.

39) Smith P, Bielecky A, Mustard C. The relationship between chronic conditions and work-related injuries and repetitive strain injuries in Canada. $\mathrm{J}$ Occup Environ Med 2012; 54: 841-6.

40) Palmer KT, Harris EC, Coggon D. Chronic health problems and risk of injury in the workplace: a systematic literature review. Occup Environ Med 2008; 65: 757-64.

41) Chau N, Lemogne C, Legleye $S$, et al. Are occupational factors and mental difficulty associated with occupational injury? J Occup Environ Med 2011; 53: 1452-9.

42) Toppinen-Tanner S, Kalimo R, Mutanen P. The process of burnout in white-collar and blue-collar jobs: eight-year prospective study of exhaustion. J Organ Behav 2002; 23: 555-70.

43) Lindblom KM, Linton SJ, Fedeli C, Bryngelsson I-L. Burnout in the working population: relations to psychosocial work factors. Int J Behav Med 2006; 13: 51-9.

44) Toppinen-Tanner $S$, Ahola K, Koskinen A, Väänänen A. Burnout predicts hospitalization for mental and cardiovascular disorders: 10-year prospective results from industrial sector. Stress Health 2009; 25: 287-96.

45) Brenninkmeijer V, van Yperen NW. How to conduct research on burnout: advantages and disadvantages of a unidimensional approach in burnout research. Occup Environ Med 2003; 60: i16-i20. 